\title{
DESENVOLVIMENTO E MUDANÇAS CELULARES NA ESTRUTURA DOS RAIOS XILEMĀTICOS DE Rollinia Emarginata Schlecht. (ANNONACEAE).
}

Paulo Cesar Botosso

Departamento de Produtos Florestais (DPF). Instituto Nacional de Pes quisas da Amazônia (INPA). Manaus, AM.

RESUMO

Foram observados, a partir de secções longitudinais tangen ciais em sērie do cāmbio à medula, o desenvolvimento e as mais sig nificantes mudanças celulares na estrutura dos raios de Rozzinia emarginata Schlecht. (Annonaceae). As caracteristicas dos raios das camadas mais externas do xilema secundārio são descritas e as prin cipais mudanças na sua estrutura nos diferentes estágios do desenvol vimento secundārio são consideradas. As mudanças celulares observa das são extremamente variāveis, ocorrendo isoladamente ou em comple xas combinações.

As mudanças celulares mais significantes observadas duran te o desenvolvimento dos raios são as seguintes: origem de iniciais radiais a partir de iniciais fusiformes ou de iniciais radiais do câmbio; mudanças resultantes do crescimento intrusivo das iniciais fusiformes através de um grupo de iniciais radiais e a perda de in ciais radiais do câmbio. Em base destas transformações celulares são consideradas as mudanças mais importantes na origem dos raios secun dārios, aumento em altura e largura e redução na altura dos raios multisseriados.

\section{SUMMARY}

B0tosso, P.C., 1988. Cellular development and changes in the struc ture of rays in the xylem of Rozzinia emarginata Schlecht. (Annonaceae). Ciência e Natura, 10:131-145.

Through microscopical observations in serial tangential sctions from cambium to pith the development and the most significant cellular changes in the structure of rays of Rozzinia emarginata Schlecht. (Annonaceae) were observed. The ray characteristics of the outermost layer of secondary xylem are described and the major changes in the ray structure in different stages of secondary deve looment are considered. The cellular changes observed are extremely variable, occurring isolated or in complex combinations.

The most significant cellular changes observed during ray development are the following: origin of ray initials from fusiform initials or from cambial ray initials; changes resulting from the intrusive growth of fusiform initials through a group of ray in $\underline{i}$ tials and the loss of ray initials from the cambium. From these cel lular transformations the most important changes in the origin of 
secondary rays, increase in height and width and reduction in the height of multisseriate rays are considered.

\section{INTRODUÇAO}

Certos caracteres anatómicos dos raios, tais como tipo, largura e altura são frequentemente empregados tanto em estudos me ramente descritivos como sob o ponto de vista taxonômico e/ou filo genético. Geralmente nestes estudos as observações limitam-se aos raios das camadas mais externas do xilema secundārio. Segundo Barghoorn (5), por exemplo, em estudos anatōmicos comparativos a observação das partes mais internas é omitida, com a suposição de que o grau de especialização ē mais claramente indicado nas mais externas.

Baseando-se no aspecto morfológico dos raios das Dicotile dōneas nas porções mais externas do crescimento secundārio, Kribs (19) estabeleceu determinadas linhas de especialização filogenética. Este sistema apresenta uma sērie de limitações, sobretudo, aos gru pos que possuem uma ampla variação na estrutura dos raios (Barghoorn, 6).

Devido a grande variação no tipo e tamanho dos raios xile máticos na familia Annonaceae, como descrito por Wyk \& Canright (22) e Metcalfe \& Chalk (20), torna-se difīcil classificā-los exatamente em base do proposto por Kribs (19).

Durante os sucessivos estágios do crescimento secundārio, segundo Barghoorn $(6,7)$, podem ocorrer variações significativas na estrutura dos raios. 0 mesmo acrescenta que, devido a estas modifi cações os seus caracteres estruturais podem apresentar num mesmo in divỉduo distintos nīveis de especialização em diferentes estāgios do desenvolvimento ontogènico.

Aspectos dirigidos à origem, desenvolvimento e formação dos raios vasculares em Dicotiledôneas e Conỉferas tem sido exten sivamente descritos por Barghoorn $(4,5,6,7)$ e Bannan $(1,2,3)$. Outros estudos relacionados ao desenvolvimento dos raios incluem os traba 1 hos de Chattawary (8), Cumbie $(11,12,13)$ e Esau (14), Evert (15), Cheadle \& Esau (9), Philipson et al. (21) e Zimmermann \& Brown (23). Neste sentido, o presente trabalho visa mostrar o desen volvimento e as principais modificações celulares dos raios de Rolli nia emarginata (Schlecht.), procurando contribuir ao conhecimento da ontogenia dos raios da familia Annonaceae.

\section{MATERIAL E METODOS}

Foram utilizadas amostras de 3 individuos de "araticum mi rim", Rolzinia emarginata Schlecht. (Annonaceae), espēcie de häbito arbustivo com ocorrência natural em āreas de dunas do Estado de San ta Catarina. O material coletado foi seccionado e fixado em solução de F.A.A. (formol, àcido acético glacial e àlcool etîlico 70\%), na 
proporção de 5:5:90 cc (Johansen, 18).

os bloquinhos foram devidamente orientados nos planos de corte: transversal, longitudinais radial e tangencial. As amostras destinadas às medições de comprimento das iniciais fusiformes do câm bio form subtetidas à inclusão em Polietilenoglicol (Freund, 16). Foram efetuados cortes em sērie, segundo o plano longitudinal tangen ciał em micrótomo de deslizamento, com espessura ajustada de $16 \mathrm{~m}$ crōmetros. 0s cortes na região cambial foram realizados de modo a obter secções anatômicas das células iniciais cambiais e das primei ras cēlulas imediatamente derivadas a partir destas células, antes da diferenciação. Foram realizadas 100 medições de comprimento das iniciais fusiformes por individuo amostrado.

Como método de coloração utilizou-se safranina e azul de Astra. A montagem, em lâminas permanentes, foi realizada empregan do-se resina sintética Permount. Para a descrição anatômica dos raios seguiu-se as recomendações da COPANT (10). A terminologia segue 0 estabelecido pela Associação Internacional de Anatomistas da Made ra. (IAWA, 17).

Os aspectos da modificação celular na estrutura dos raios nos diferentes estágios de desenvolvimento foram considerados de acordo com o mätodo empregado por Barghoorn $(4,5,6,7)$ e Cumbie (11, 12,13) no estudo das mudanças no desenvolvimento do xilema e câmbio vascular. Este método consiste, essencialmente, em analisar as alte rações na estrutura do xilema atravēs de secções longitudinais tan genciais em sêries devidamente orientadas do câmbio à medula.

\section{RESULTADOS E DISCUSSAO}

Os raios de Rollinia emarginata prōximos à camada mais ex terna do xilema secundārio refletem uma estrutura tipicamente homo gēnea a fracamente heterogēnea (Kribs, tipo I e II). Predominam os raios normais, não estratificados, de pouco a numerosos ( 3 - $\underline{6} 10$ raios/mm). Raios unisseriados pouco frequentes em relação aos mu 1 tisseriados; extremamente finos a muito finos $(8-\underline{15}-25 \mu \mathrm{m})$, ex tremamente baixos $(40-\underline{113}-283 \mu \mathrm{m})$, e com $2-\underline{4}-9$ células de altura. Raios multisseriados normalmente apresentando em suas mar gens células mais altas e curtas, porém procumbentes, às vezes, cé lulas levamente quadradas entremeadas nos raios; extremamente baixos a baixos $(210-\underline{455}-1250 \mu \mathrm{m})$, com 8 - $\underline{20}-63$ células de altura; estreitos $(28-\underline{62}-113 \mu \mathrm{m})$, e com $2-\underline{3}-5$ células de largura (Figuras la, 1b).

Devido a grande variação na estrutura dos raios torna-se difícil classifica-los exatamente segundo o sistema sugerido por Kribs (19). Este aspecto pode ser observado através da Figura 2, na qual estão ilustrados alguns padrões anatômicos mostrando a variabi lidade estrutural existente nos raios tanto uni como multisseriados. 

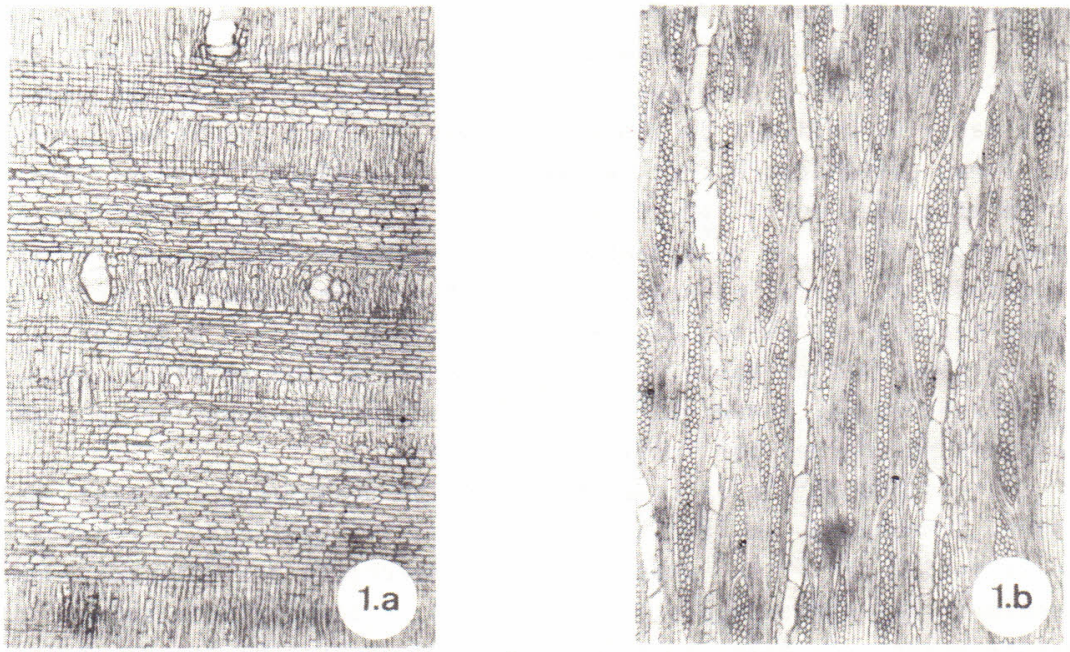

Figura 1 - Aspectos anatōicos dos ralos de Rollinia amarinata. Figu ra 1.a, secção longitudinal radial; e Figura 1.b, secção longitudinal tangencial, (X50).

Neste sentido, hā uma concordância com a afirmação de Wyk \& Canright (22), acerca da dificuldade em classificá-los segundo Kribs. Em vír tude disto, tambëm Metcalfe \& Chalk (20) os descreveram como tipica mente ou quase totalmente homogēneos (Kribs, tipo I e II), ainda que, algumas vezes distintamente heterogēneos com notāveis diferenças no tamanho e forma das cēlulas procumbentes, mesmo em espécies do mes mo gênero.

Embora o sistema proposto por Kribs (19) seja bastante uti lizado por anatomistas de madeira em trabalhos descritivos, taxonō micos e/ou filogenéticos, o mesmo apresenta algumas limitações pois restringe os detalhes anatōmicos dos raios a um minimo. Barghoorn (6), ao realizar estudos sobre o desenvolvimento ontogenético dos raios de Dicotiledōneas demonstrou certas restrições quanto ao seu emprego. A estrutura dos raios pode apresentar uma série de modif $\underline{i}$ cações celulares que acarretam em mudanças quanto ao tipo deste ca rāter nos diferentes estágios do crescimento secundārio. Como ilus tram as Figuras 3.a - 3.c, os raios xilemäticos desta espécie demons tram expressivas alterações celulares durante estes estāgios.

Estas modificações na estrutura dos raios aumentam a difi culdade em utilizá-1os como carāter, especialmente, em estudos filo genēticos. Como elementos de valor à identificação, os aspectos de altura e largura dos raios, podem ser de pouco valor diagnóstico. Pa ra Barghoorn (5), estes aspectos deveriam ser empregados com pre caução.

Desde a sua estrutura prōxima ao corpo primārio (Figuras 

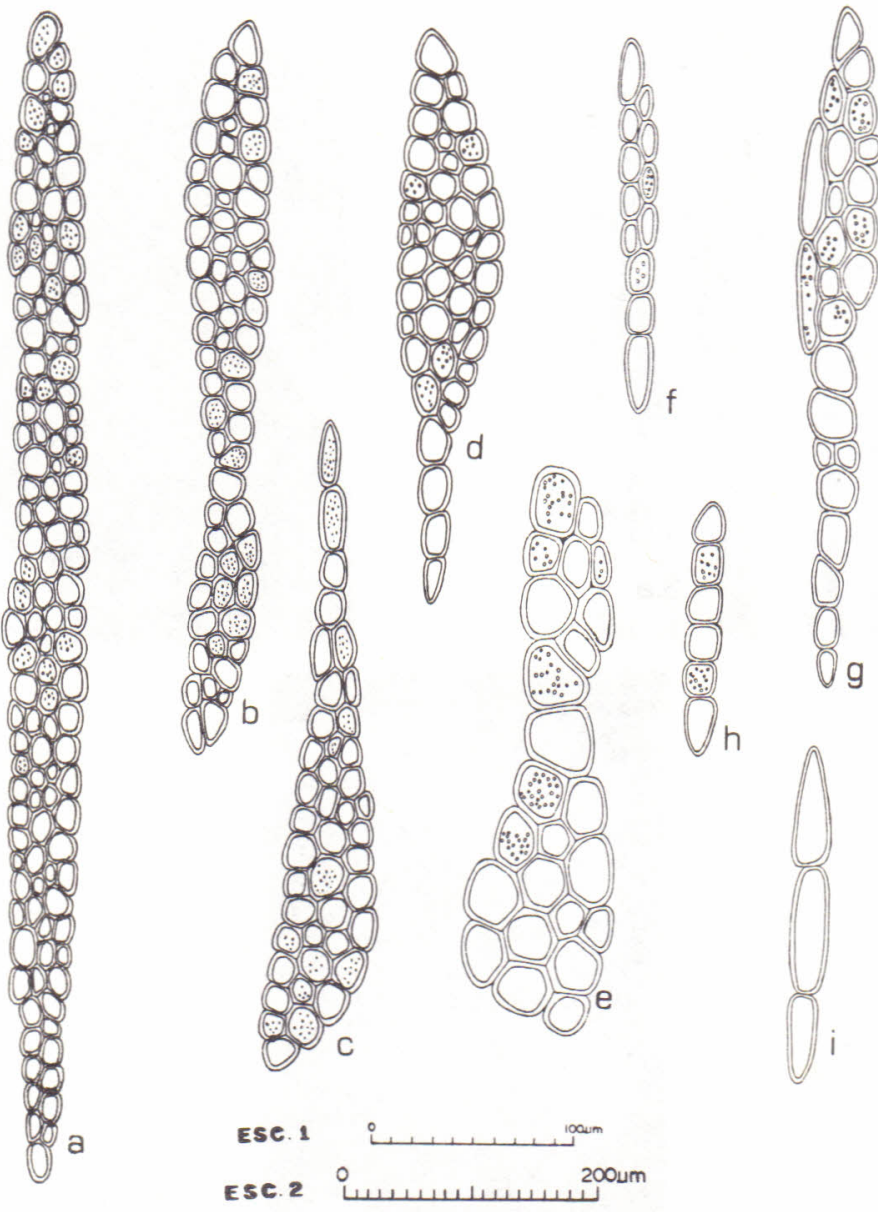

Figura 2 - Alguns padrões anatômicos dos raios no xilema secundärio de Rolzinia emarginata vistos em secções tangenciais. a $\underline{g}$, raios multisseriados; $\underline{h}, \underline{i}$, raios unisseriados (escala 1, a - d); escala 2, e - i).

4.a e 4.b) atē seu desenvolvimento às camadas mais externas do corpo secundärio em direção ao cāmbio (Figura 4.g), pode-se ter um exemplo das mudanças que ocorrem num mesmo raio. Nos primeiros estāgios de desenvolvimento, pröximos ao corpo primärio, observa-se a presença de raios tanto uni como multisseriados estendendo-se dos segmentos fasciculares e interfasciculares do estelo, embora que os unisseria dos sejam nitidamente menos freqdentes (Figura 5). Mesmo nos primei ros estägios de ontogenia, verifica-se uma tendência à eliminação dos raios unisseriados pela sua transformação em unidades multisseriadas. Este aspecto persiste por todas as fases do desenvolvimento dos raios 

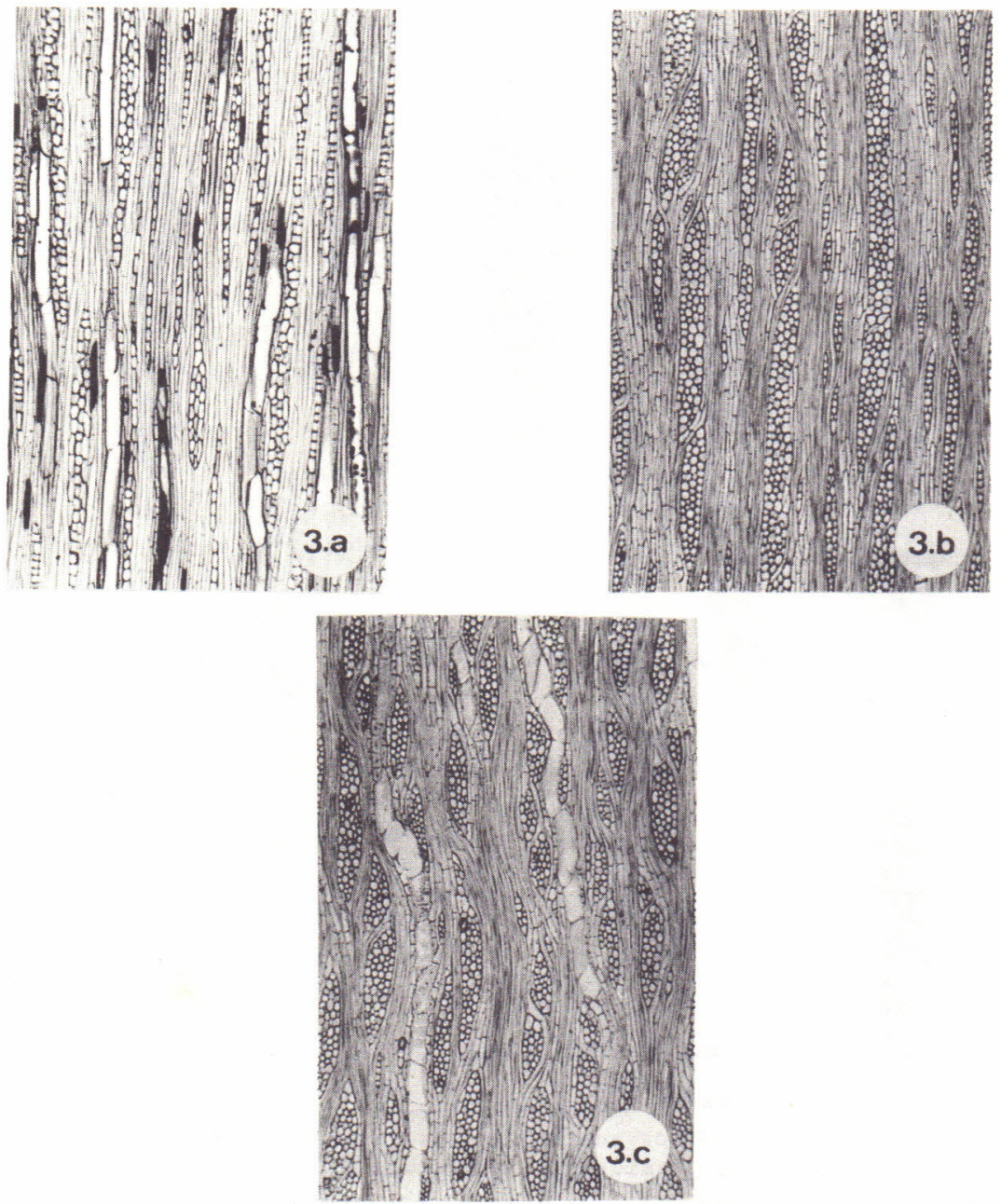

Figura 3 - Secções longitudinais tangenciais mostrando os sucessivos estägios no desenvolvimento dos raios. Na Figura $3 a$, es trutura dos raios prōximos à medula; Figura 3b, estrutu ra em posição mediana; e Figura 3.c, aspecto dos raios prōximos às camadas mais externas do xilema secundārio $(\times 53)$.

atē as ūltimas camadas formadas pelo crescimento secundārio.

$\mathrm{Na}$ transição dos raios primārios às partes mais internas do crescimento secundārio, observa-se uma rāpida mudança no formato e orientação das cēlulas. Os raios primārios são constituīdos basi camente por cēlulas irregulares e eretas (Figura 6). A transição 


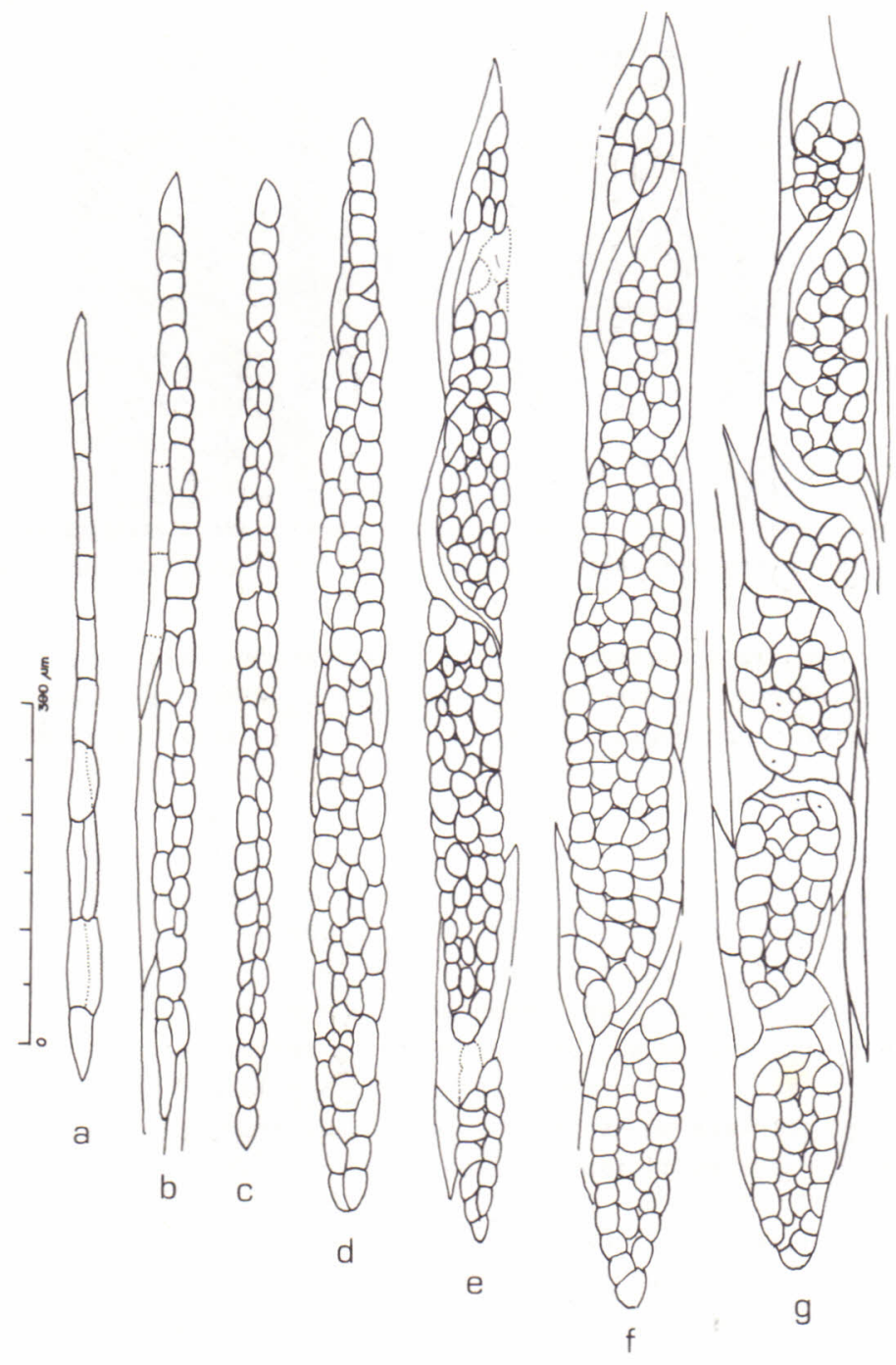

Figura 4 - Secções longitudinais tangenciais em sērie mostrando as modificações estruturais ocorridas num mesmo raio em di ferentes estāgios de desenvolvimento. (Intervalo entre as secções $\underline{\text { a }}$ - $\underline{g}$, aproximadamente $5 \mathrm{~mm}$ ).

para uma condição menos heterogēnea é observada no carāter destes raios à medida que se distanciam do corpo primārio. Para Wyk \& Canright (22), tal condição para Annonaceae sugere uma modificação ontogēn i ca dos raios à homogeneidade. Esta alteração no formato das cēlulas é precedida por divisões celulares no plano transversal das iniciais 


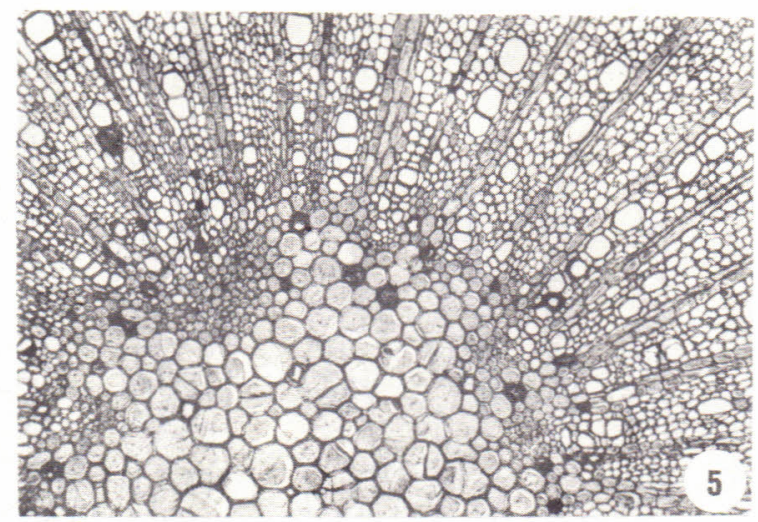

Figura 5 - Secção transversal do caule, mostrando a presença de raios tanto uni como multisseriados estendendo-se dos segmen tos fasciculares e interfasciculares. ( $(x 83)$.

radiais, as quais diminuem de altura nas camadas mais internas do $x$ lema secundārio. Em função destas divisões, evidencia-se uma mudan ça do maior comprimento das células do sentido axial vertical ao pla no radial. Embora ocorrendo a divisão destas iniciais em derivadas menores, não se constatou uma redução na altura dos raios primärios. Segundo Philipson et al. (21), em contraste à situação em Conỉferas, nas Dicotiledóneas os raios primärios são raramente reduzidos na al tura como resultado do crescimento radial das cēlulas.

Com a produção do tecido vascular secundārio a partir do câmbio o caule aumenta em circunferência e os raios primārios cres cem, distanciando-se do corpo primārio. A medida que isto se proces sa, novos raios são formados. Estes são os raios secundārios e sua formação contribue no sentido de manter uma proporção mais ou menos constante entre os tecidos horizontal e vertical no cilindro vascu lar.

Durante o desenvolvimento dos raios secundārios observam-se complexas mudanças celulares, as quais implicam em modificações na sua estrutura. Estas mudanças podem ocorrer isoladamente, mas com frequência envolvem complexas combinações. Em muitas delas, torna-se difîcil distinguir qual alteração estā ocorrendo, devido a grande plasticidade das iniciais cambiais. Dentre estas mudanças celulares as mais significativas foram: a) origem de novas iniciais radiais a partir de iniciais fusiformes ou de radiais do pröprio cámbio; crescimento intrusivo apical das iniciais fusiformes, e, c) elimina ção de células iniciais radiais do cāmbio.

As novas células radiais originam-se mais frequentemente de iniciais fusiformes adjacentes aos raios secundārios do que por divisões anticlinais das prōprias iniciais radiais. A partir desta 
transformação, as mais expressivas mudanças observadas foram as se guintes: formação de novos raios secundārios, fusão e aumento em a tura e largura dos mesmos.

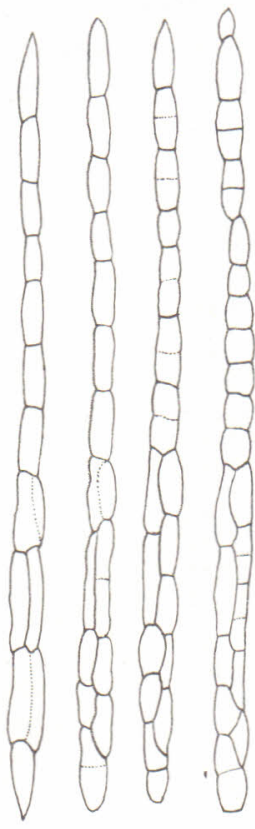

a

b c

d

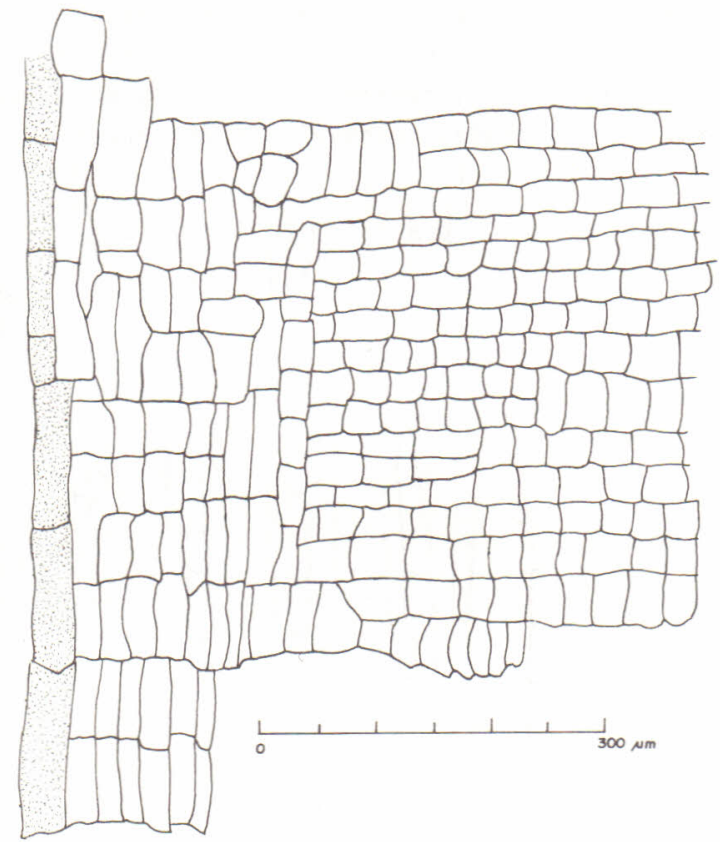

e

Figura 6 - Aspectos anatōmicos dos raios; Figuras 6.a - 6.d, secções tangenciais em série de um raio das camadas mais internas prōximas ao corpo primārio; Figura 6.3, secção longitudi nal radial das partes mais internas do xilema secundārio com o xilema primārio (indicado pelas āreas pontilhadas).

A formação de novos raios resulta basicamente da simples segmentação de iniciais fusiformes isolados (Figura 7), por meio de divisões transversais formando uma fileira de iniciais radiais, ou a partir da extremidade das células iniciais fusiformes (Figura 8) (Zimmermann, 23; Philipson et a1.,21). Como enfatizado por Cumbie (13), e observado para esta espécie, as novas células radiais são formadas por divisão das iniciais fusiformes, sem qualquer perda ou decréscimo no comprimento destas cēlulas.

Acompanhando o rápido aumento em circunferência do câmbio vascular, observa-se nesta espēcie uma tendēncia ao alargamento dos raios secundārios uni e multisseriados. Este aumento em largura en volve a produção de novas iniciais radiais a partir de iniciais fu siformes, acréscimos laterais de novas células radiais e fusão de 
raios contíguos (Cumbie, 11, 12). Verifica-se que, o aumento em lar gura dos raios ocorre, principalmente, pela conversão de porções ou mesmo de células iniciais fusiformes inteiras em iniciais radiais acrescidas aos lados dos raios (Figura 9), do que por divisões das prōprias iniciais no interior dos raios. Por outro lado, o aumento em altura ocorre, geralmente, pela formação de novas cēlulas origi nadas por divisões transversais das próprias cēlulas radiais.

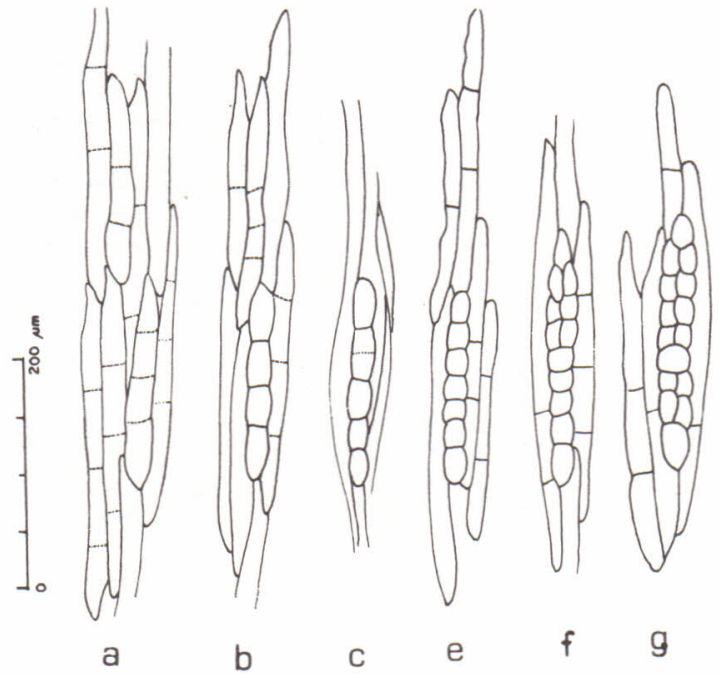

Figura 7 - Secções longitudinais tangenciais em série, mostrando a origem de novos raios pela segmentação das células in ciais fusiformes. (Intervalo entre as secções $\underline{a}-\underline{g}$, apro ximadamente $500 \mu \mathrm{m})$.

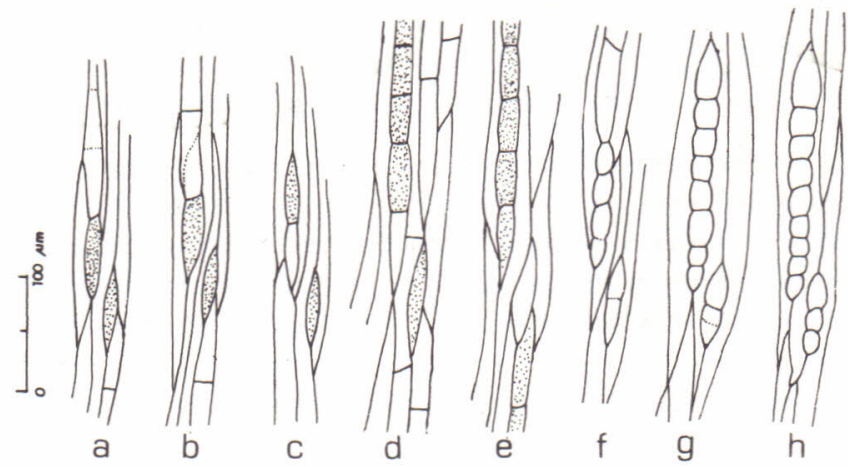

Figura 8 - Seç̧ões em sērie, ilustrando a origem de iniciais radiais a partir da extremidade de iniciais fusiformes. (Interva 10 entre as secções $\underline{a}-\underline{g}$, aproximadamente $140 \mu \mathrm{m})$.

os raios unisseriados alargam-se inicialmente por meio de divisões no plano anticlinal longitudinal tornando-se bisseriados 
(Figuras 10.a - 10.c); havendo uma tendéncia a se fusionarem, quando adjacentes. Como mostra a Figura 10, esta fusão se processa median te a transformação de iniciais fusiformes em novas células de raio. Esta tendência condiz com a afirmação de Barghoorn (6), o qual con sidera que durante o crescimento secundārio os raios unisseriados au mentam em largura, tornando-se multisseriados para, posteriormente, separarem-se em unidades menores.

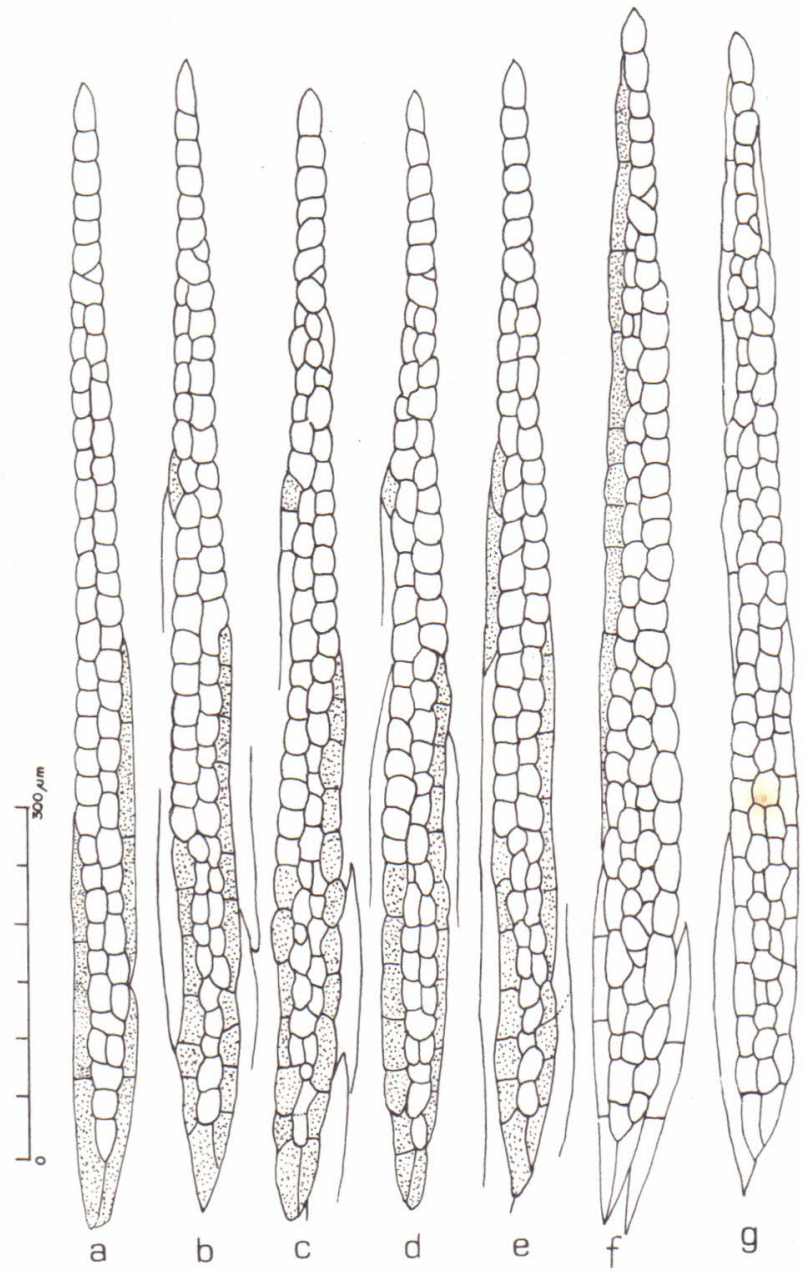

Figura 9 - Secções longitudinais tangenciais em sērie, mostrando o aumento em largura de um raio multisseriado pelo acrésci mo lateral de novas cêlulas radiais. (Intervalo entre as secções a - g, aproximadamente $180 \mu \mathrm{m})$.

o processo de separação dos raios multisseriados em pequenas 
unidades (Figura 11) è resultado do crescimento intrusivo apical das iniciais fusiformes, precedido pela eliminação das iniciais radiais do càmbio (Figura 12), facilitando a sua entrada através do raio. Esta eliminação pode envolver as células radiais tanto das margens quanto das camadas mais centrais dos raios. Para esta espécie, estas são as alterações mais expressivas responsáveis pela redução na al tura dos raios secundários.

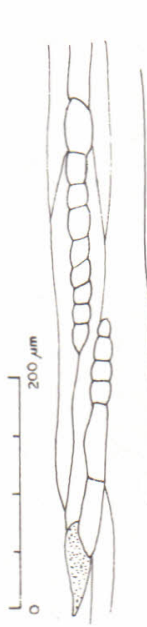

a

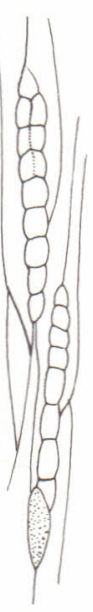

b

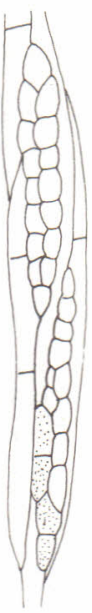

C

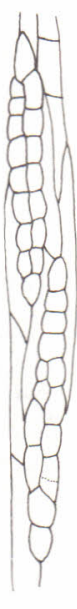

d

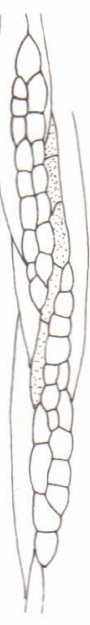

e

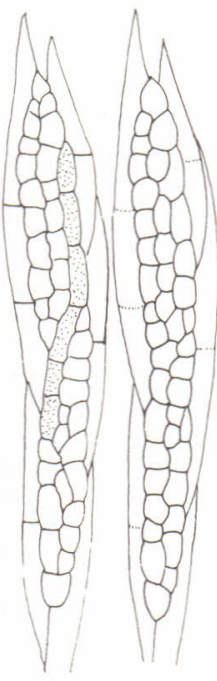

g

Figura 10 - Secções em série, mostrando a fusão de dois raios pela transformação de uma célula inicial fusiforme em iniciais radiais. (Intervalo entre as secções a - $\underline{g}, 380 \mu \mathrm{m}$ ).

Apesar das iniciais fusiformes serem relativamente curtas $(170-274,2-410 \mu \mathrm{m})$, em geral, estas sofrem um intenso crescimen to intrusivo apical apōs as divisões anticlinais no câmbio. As mu danças decorrentes deste crescimento desempenham um importante papel na ontogenia dos raios. Os pequenos raios multisseriados originados desta separação divergem radialmente, a medida que se expande o cor po secundário. Para Barghoorn (5), por outro lado, o ma is significa tivo fator de redução na altura dos raios secundārios se deve à con versão de iniciais radiais em iniciais fusiformes. Todavia, para es ta espécie, uma concordāncia é verificada com a opinião de Esau(14), Evert (15), Cheadle \& Esau (9), os quais constataram que a divisão dos raios ocorre, geralmente, como um resultado do crescimento in trusivo de iniciais fusiformes atravês de um grupo de cēlulas ra diais e que a separação resultante da conversão é, provavelmente, menos comum. Para Philipson et al. (21), a conversào é comum em 
Dicotiledōneas, ocorrendo mais frequentemente nas partes centrais dos raios multisseriados. 0 mesmo acrescenta que o crescimento des tas células radiais em fusiformes não ocorre em todas Dicotiledōneas.
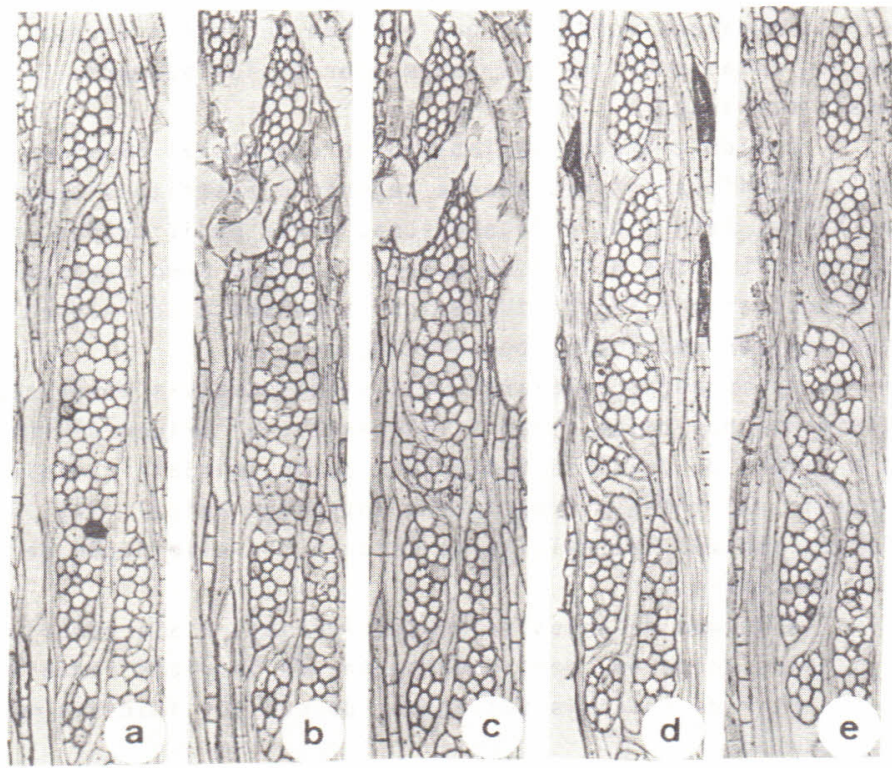

Figura 11 - Secções longitudinais tangenciais em sērie, mostrando a separação de um raio multisseriado em unidades menores pelo crescimento intrusivo apical das iniciais fusifor mes atravēs do raio. Intervalo entre a - e; aproximada mente $240 \mu \mathrm{m}(\times 106)$.

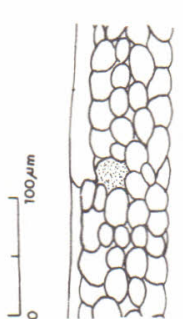

a

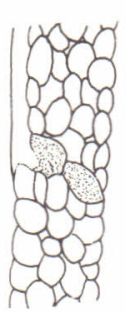

b

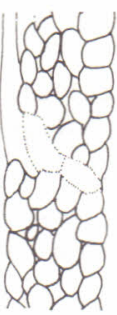

C

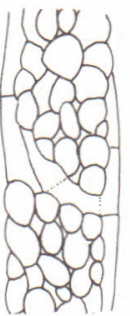

d

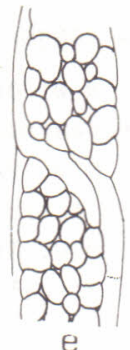

e

Figura 12 - Secções em sērie, mostrando a separação de um raio pelo crescimen.to intrusivo das iniciais fusiformes. Note que as iniciais radiais são eliminadas do câmbio, facilitan do a entrada das iniciais fusiformes no raio. (Interva 10 entre secções a - e, aproximadamente $230 \mu \mathrm{m})$. 
CONCLUSOES

Analisando-se as alterações ontogenēticas na estrutura dos raios de Rolzinia emarginata, a partir de secçoes longitudinais tar genciais em série do câmbio à medula, foi possivel reconstruir as principais mudanças celulares que ocorrem durante o desenvolvimentc dos raios. Estas modificações podem ocorrer isoladamente ou comc complexas combinações.

Devido a grande variabilidade estrutural observada torna-se difícil classificá-los exatamente segundo o restrito sistema propos to por Kribs. Para fins filogenéticos, estas modificações podem re presentar diferentes nīveis de especialização. Como caracteres de valor diagnóstico à identificação, os aspectos tipo, altura e largu ra deveriam ser empregados com precaução.

As mudanças celulares ma is significativas observadas no de senvolvimento dos raios foram as seguintes: a) origem de iniciais ra diais a partir de iniciais fusiformes ou de iniciais radiais do pró prio càmbio; b) intenso crescimento intrusivo apical das iniciais fusiformes atravēs das cēlulas do raio; e, c) eliminação de iniciais radiais do câmbio.

A origem de novos raios secundārios, o alargamento e a fu são dos raios decorrem, particularmente, de iniciais radiais origi nadas a partir de iniciais fusiformes do que por iniciais radiais do prōprio cāmbio.

Durante o crescimento secundārio hā uma.tendēncia à elimi nação dos raios unisseriados. Estes raios, por sua vez, alargam-se tornando multisseriados para, posteriormente, separarem-se em unida des menores. 0 processo de redução na altura dos raios multisseria dos envolve, basicamente, a separação dos raios em unidades menores, como resultado do crescimento intrusivo apical das iniciais fusifor mes através do raio precedido pela eliminação de iniciais radiais.

\section{LITERATURA CONSULTADA}

1. Bannan, M.W. Origin and cellular character of xylem rays in gymnosperms. Bot. Gaz. 96:260-81, 1934.

2. Bannan, M.W. Vascular rays and adventitious root formation in Thuja occidentalis L. Am. J. Botany 28: 457-63, 1941.

3. Bannan, M.W. The frequency of anticlinal divisions in fusiform cambial cells of Chamaecyparis. Am. J. Botany, 37:511-19, 1950.

4. Barghoorn, Jr., E.S. Origin and development of the uniseriate rays in the Coniferae. Bulletin of the Torrey CZub, 67:303-28, 1940a.

5. Barghoorn, Jr. E.S. The ontogenetic development and phylogenetic specialization of rays in the xylem of Dicotyledons. I. The primitive ray structure. Amer. J. Botany, 27:918-28, 1940b.

6. Barghoorn, Jr. E.S. The ontogenetic development and phylogenetic specialization of the rays in the xylem of Dicotyledons. II. 
Modification on the multiseriate and uniseriate rays. Amer. J. Botany, 28:273-82, 1941a.

7. Barghoorn, Jr. E.S. The ontogenetic development and phylogenetic specialization of rays in the xylem of Dicotyledons. III. The elimination of rays. Buzz. Torrey Bot. Club, 68:317-25, 1941b.

8. Chattaway, M.M. The wood anatomy of the Family Sterculianeae. Phiz. Trans. Roy. Soc., 228:313-65, 1937.

9. Cheadle, V.I. \& Esau, K. Secondary phloem of Liriodendron tuli pifera. Uni. Calif. Publ. Bot. 36:143-252. 1964.

10. Comission Panamericana de Normas Técnicas. 30: 1-019, novembro, 1973.

11. Cumbie, B.G. Developmental changes in the vascular cambium of the Polygonum Zapathifolium. Amer. J. Bot., 56:139-46, 1969a.

12. Cumbie, B.G. Developmental changes in the xylem and vascularcam bium of Apocynum sibiricum. Buzz. Torrey Botanical Club, 96 (6): $629-40,1969 b$.

13. Cumbie, B.G. Developmental changes in the wood of Bocconia vul canica Donn. Smith. IAWA Buzl., n.s. vol.4 (2-3):131-40, 1983.

14. Esau, K. Plant Anatomy. New York, John Wiley \& Sons. 1965, 767p.

15. Evert, R.F. Some aspects of cambial development in pyms communis. Am. J. Bot., 48: 479-88, 1961 .

16. Freund, H. Handbuch der Mikroskopie in der Technik. Frankfurt, Umschan Verlag. 1970, v.5, pt. 2, 379 p.

17. IAWA Committee on Nomenclature. Multilingual glossary of terms used in wood anatomy. Konkordia, Winterthur. 1964. 186 p.

18. Johansen, D.A. Plant Microtechnique. McGraw-Hill, New York, $1940,523 \mathrm{p}$.

19. Krigs, D.A. Salient lines of structural specialization in the wood rays of Dicotyledons. Bot. Gaz., 96:547-57, 1935.

20. Metcalfe, C.R. \& Chalk, L. Anatomy of Dicotyledons. Oxford, Claredon Press, Vol. I, 1972, $724 \mathrm{p}$.

21. Philipson, W.R.; Ward, J.M. \& Butterfield, B.G. The vascular cam bium. Chapman \& Hall Ltd., London, 1971, 181 p.

22. Wyk, R.W. van der \& Canright, J.E. The anatomy and relationships of the Annonaceae. Tropical Woods, 104:1-24, 1956.

23. Zimmermann, M.H. \& Brown, C.L. Trees: structure and function. Springer-Verlag, New York, 1977, $336 \mathrm{p}$.

Recebido em outubro, 1988; aceito em dezembro, 1988. 
